\title{
Justification of the territorial location of «green energy» objects in relation to the needs of the Tyumen region
}

\author{
Larisa Filimonova*1, Elena Matys $^{1}$, Aleksandr Sbitnev ${ }^{10000-0002-8663-1959]}$, Elena Juze ${ }^{1}$, and \\ Anastasia Bokova ${ }^{2}$ \\ ${ }^{1}$ Industrial University of Tyumen, 625000 Tyumen, Russia \\ ${ }^{2}$ Architect construction company, 625547 Tyumen, Russia
}

\begin{abstract}
In modern conditions of falling business activity of enterprises and falling incomes of the population, the growing trend of electricity shortages persists. This need may be aggravated by the high level of deterioration of equipment at Russian thermal power plants. All world practice shifts the guidelines for expanding electricity production towards the creation of a market for pre-fabricated renewable energy sources. In the article, the authors focused on justifying the need for the massive construction of wind power plants as an alternative source of energy. Today, «traditional» energy sources cannot meet the growing demand in remote areas of the Tyumen region with districts in the context of the spread of modern information technologies and the process of digitalization of public services. The current situation also imposes significant restrictions on the intensity of the development of the process of educational technologies in remote settlements. In this connection, the authors of the article decided to conduct an analytical study to substantiate the ways of territorial development through the launch of projects for the construction of compact wind power plants as an alternative source of energy in providing resources to remote settlements.
\end{abstract}

Keywords. Wind turbine, renewable sources, land plot, land category, construction project.

\section{Introduction}

The wind energy market in Russia is significantly inferior to countries with a developed direction of using alternative energy. The total installed capacity of wind power plants (hereinafter WEC) in the world today is estimated at $500 \mathrm{GW}$, the maximum share of which is $80 \mathrm{GW}$ and belongs to China. The leaders, according to the report [1], as of January 21, 2021 are: China, USA (60 GW), Germany (30 GW), Spain, India, Norway, Italy, Denmark, France, Canada, Brazil. At the same time, the European Union accounts for a total of 100 GW. There was no wind power in China 10 years ago. Today this country is represented by such largest wind energy facilities as, for example, VES Gancy (7965 MW). The breakaway from the rest of the world is large, and this is explained by the greater investment in the use of wind energy, the adoption of state-owned programs for the development of renewable

*Corresponding author: Filimonovala@tyuiu.ru 
energy [1]. In turn, world practice is more often focused on mini and medium-level projects for the construction of wind farms, on the development of compact wind turbines for a small number of consumers, in contrast to China.

In accordance with the Federal Law of the Russian Federation № 35 «On the Electricity Industry» dated March 26, 2003, which, within the framework of activities in the retail market, states: "Grid organizations must compensate for losses in electrical networks primarily through the purchase of electrical energy produced at qualified generating facilities, connected to the networks of grid organizations and operating on the basis of the use of renewable energy sources» Russia is reconfiguring to use new types of energy sources.

The development of the park involves the creation of the first wind power plant in the Russian Federation, supplying electricity directly to the power grid. This project falls under the definition of a qualified generating facility and can be connected to the networks of PJSC Fortum [2], which will be the main buyer of energy. In addition, it is possible to connect private manufacturing companies to the system to meet their own needs. Again, we are talking about megaprojects [3] and the preservation of the monopoly of the energy market.

In most of Russia, electricity is supplied to consumers from the wholesale market. Let us separate the price and non-price zones of the wholesale market. In the price zones, electricity is supplied to consumers (except for the population) at unregulated prices. In non-price zones, market pricing is currently considered impossible for various reasons; therefore, purchases on the wholesale market are carried out at state-regulated prices [4-6]. The cost of energy resources for the consumer consists of two components: the selling price from the energy source and the tariff for the provision of services for the delivery of energy through power grids to the final consumer. The price of electricity, as a social factor in the formation of objective prerequisites for overcoming the social crisis of 2020-2021, should be acceptable for buyers. Moreover, it should have a downward trend, which would stabilize prices on the Russian energy market.

For the stable development of the national economy, first of all, it is required to protect the energy producer from the negative influence of external factors. We are talking about fluctuations in the cost of primary energy resources due to the uncertainty of world prices for coal, gas and oil products.

The industrialized countries with limited natural resources have been busy solving this problem for more than one decade. The accumulated experience in the implementation of economic activities of the energy complex of European countries, China gives a clear focus on renewable sources of resources, such as light, water, wind, which ensures the financial feasibility of projects to modernize their national traditional energy. Experience shows that electricity produced from renewable resources is affordable due to the minimization of material costs for the primary energy resource.

Reasonable pricing policy throughout the entire production cycle of delivering electricity to the final consumer allows the national economy to compete in the world market with goods with high added value.

The authors of the article have systematized the key advantages of launching a project for the construction of wind power plants (WPPs) at the middle level in terms of scale:

- Wind farms are not subject to the fuel situation, since the primary energy carrier, wind, has no value, which significantly reduces the cost of electricity produced on them;

- in the conditions of the Tyumen region, it is possible to build wind farms near the centers of electricity consumption, which reduces the tariff for its delivery, as well as losses in power grids in comparison with its sale by other suppliers;

- the construction time of wind farms is very short (up to two years for wind farms with a capacity of about 50 thousand $\mathrm{kW}$ );

- there are no environmental problems in the production of electricity at the wind farm, since there are no emissions into the atmosphere; 
- electricity prices are increasing due to its growing deficit caused by high wear and tear of equipment in the energy complex.

This publication is based on the following hypothesis: if a park with a well-developed and well-founded concept appears on the territory of the region, this will solve the problem of remote areas with energy supplies. It can give an impetus for the development of several areas of the energy and industrial sectors of the region at once, and also contribute to the further development of wind energy in Russia.

\section{Methods}

«The main directions of the development of the world energy are already visible: under the influence of changes in energy policy and the development of new technologies, the world is entering the stage of the 4th energy transition to the widespread use of renewable energy sources and the displacement of fossil fuels» [6].

According to statistics, primary energy consumption will slow down significantly by 2040, including, due to energy efficiency. Thus, by 2040, the rapid development of renewable energy sources will provide $35-50 \%$ of world electricity production and $19-25 \%$ of total energy consumption. Of the fossil fuels, only gas will be able to increase its share in the global energy balance from $22 \%$ to $24-26 \%$, while coal will reduce from $28 \%$ to $19-23 \%$ [7].

Table 1. The structure of the Russian energy sector.

\begin{tabular}{|l|c|c|}
\hline \multicolumn{1}{|c|}{ Power plants } & Installed capacity, MW & Share in installed capacity, \% \\
\hline $\begin{array}{l}\text { Power plants Russia, total } \\
\text { Including }\end{array}$ & 246656.53 & 100 \\
\hline thermal power plant (thermal) & 164886.22 & 66.85 \\
\hline hydroelectric station (hydraulic) & 49870.29 & 20.22 \\
\hline nuclear power plants (nuclear) & 30313.18 & 12.29 \\
\hline wind farms (wind farms) & 184.12 & 0.07 \\
\hline solar power plants (solar) & 1402.72 & 0.57 \\
\hline
\end{tabular}

In addition to the basic regulatory documents for the development of project documentation, the Urban Planning Code of the Russian Federation and the Decree of the Government of the Russian Federation № 87 are presented in table 1, a set of documents required for the development of our project of the building of the crime scene is presented.

The use of alternative energy sources in Russia, as noted in Table 1, is poorly developed. The reason for this situation is [8-11]:

1. Energy redundancy of traditional sources and the monopoly of wholesale suppliers, which is present in the country as a whole;

2. The inability of the consumer to independently resolve the issue of choosing a supplier and source of energy resources, especially during the Soviet era;

3. Lack of initiative, special knowledge and technologies that impede the development of alternative energy directions

In 2019-2024, 3.94 GW of green energy capacity should be commissioned in Russia, such targets are set by the government of the Russian Federation, which is amending the Main Directions of State Policy in the Field of Increasing Energy Efficiency in Electricity Based on Renewable Energy Sources (RES) until 2024. Experts say that sustainable development of the renewable energy sector in Russia is possible only if the government generates investment signals in a timely manner.

The fact that green energy in Russia is already cheaper than a number of new construction projects for traditional generation is an indisputable fact - the cost of renewable energy is below 3.8 rubles/kWh, against 6 or more rubles per $\mathrm{kWh}$ of thermal and nuclear generation, 
- said the director of the Association for the Development of Renewable Energy Alexei Zhikharev. - At the same time, a further reduction in the cost of green energy is predicted as the cost and efficiency of technologies continue to decrease. Today, it is impossible to make a decision regarding the development of the most promising direction of the world energy on the basis of the leftover principle.

The potential for RES development in Russia is huge, and in all segments, both in the wholesale and retail markets, and in the microgeneration segment. Today it is important to actively adapt market mechanisms to the introduction of renewable energy sources and other innovative technologies, energy storage devices. Global trends give no reason to doubt that the transformation processes will bypass the UES of Russia [12].

The power system of the Tyumen region is a part of the united power system (UES) of the Urals and has electrical connections of $500 \mathrm{kV}$ and lower voltage class with the power systems of the Sverdlovsk, Kurgan and Omsk regions, the power system of KhMAO - Yugra, as well as with the unified power system (UES) of the Republic of Kazakhstan [5-7, 12].

Next, we present a set of legal and regulatory framework governing the procedure for choosing a wind farm location.

According to Article 3 of the Federal Law № 35 of March 26, 2003 (as amended on December 27, 2019) «On Electricity», the definition of renewable energy sources can be briefly presented as follows: solar energy, wind energy, water energy (including energy wastewater), with the exception of the use of such energy at pumped storage power plants, tidal energy, wave energy of water bodies, including reservoirs, rivers, seas, oceans, geothermal energy using natural underground heat carriers, low-potential thermal energy of the earth, air, water using special heat carriers, biomass, which includes plants specially grown for energy production, including trees, and also production and consumption waste, with the exception of waste obtained in the process of using hydrocarbon raw materials and fuel, biogas, gas emitted by production and consumption waste at landfills of such waste, gas generated at coal mines.

The next important source regulating the provision of a land plot for the implementation of an investment project at the federal level is the Town Planning Code (hereinafter referred to as the Civil Code of the Russian Federation) Federal Law № 190 dated December 29, 2004.

In accordance with clause 5.1 of article 6 and clause 3.4 of article 49 of the Civil Code, a state examination of the results of engineering surveys and design documentation should be carried out in relation to unique objects. To substantiate the correctness of the calculation of loads on the foundation, scientific work must be performed.

But the main document governing land relations is the Land Code (hereinafter referred to as the RF LC). According to the RF LC, two articles 87 and 89 are applicable for a wind power plant project.

Therefore, as one of the fundamental documents, the Federal Law of December 21, 2004 № 172 (as amended on 05/01/2019) «On the transfer of land or land plots from one category to another» (as amended and supplemented, entered into effective from 01.07.2019) should be considered.

Therefore, along with the aforementioned normative legal acts, the laws governing the formation of a land plot should also be listed.

Thus, the construction of a wind farm should not contradict any of the clauses of article 4 of Federal Law №172 [5], which means that the transfer of land from the category of other designated purpose to the category of energy land for the implementation of the wind park project can be implemented.

\section{Results}

A wind generator (wind power plant or wind turbine for short) is a device for converting the kinetic energy of the wind flow into mechanical energy of the rotor rotation with its 
subsequent transformation into electrical energy Wind generators can be divided into three categories: industrial, commercial and domestic (for private use).

Industrial ones are established by the state or large energy corporations. As a rule, they are connected in a network, the result is a wind farm. Its main difference from traditional (thermal, nuclear) is the complete absence of both raw materials and waste. The only important requirement for a wind farm is a high average annual wind level. The power of modern wind turbines reaches $8 \mathrm{MW}$ [13-14].

The authors of the article, in justifying the design solution for the construction of a wind farm, settled on the following TEPs for the project: 14 wind turbines, of which 7 have a capacity of $2.5 \mathrm{MW}$, the rest 7 have a capacity of $3.0 \mathrm{MW}$; the height of the wind power plant is more than $100 \mathrm{~m}$. It is assumed that the wind turbine is staggered, the configuration of the site for the station does not play a special role, since the wind turbine can be located on any soil and terrain.

The main condition is to maintain the distance between the installations, for example, 1 wind turbine with a capacity of $2.5 \mathrm{MW}$ requires $>5$ hectares of land, that is, for one unit of wind turbines with a capacity of 2.5 to $3.0 \mathrm{MW}$, it takes from 5.0 to 6.0 hectares of land. Requirements for the reliability and safety of wind turbines - as for a traditional object of the fuel and energy complex.

Wind turbines are located with a reference point in the direction of the prevailing winds, that is, in the direction where the average annual wind speed is more than $6 \mathrm{~m} / \mathrm{s}$. The design of the unit allows, in the event of a change in the direction of the wind flow, to turn the turbine in the desired direction.

According to the Decree of the Government of the Russian Federation of January 15, 2019 № 5 «On Amending the Rules for Establishing Protected Zones for Electric Power Generation Facilities and Special Conditions for Using Land Plots Located within Such Zones» of the rules for establishing protected zones facilities for the production of electrical energy and special conditions for the use of land located within the boundaries of such zones, eliminated the need to establish protection zones in relation to wind power plants.

Since wind farms do not belong to critical facilities and technological violations in their work do not entail socio-economic, environmental and other consequences for the population and socially significant facilities. This solution will eliminate administrative barriers in the construction of wind farms and use the land near them fully.

With regard to the noise level produced by the wind turbine, the wind turbine should be removed from residential premises, hospitals, schools and rest homes at a distance that reduces the noise level generated by the operating wind turbine to a level of $45 \mathrm{~dB}$. Noise reduction is achieved mainly due to the correctly selected wind turbine equipment.

For example, here are the noise levels of various installations.

Table 2. Comparison of wind turbine noise with different noise sources.

\begin{tabular}{|l|c|}
\hline Noise source & The amount of noise, decibels \\
\hline Airplane turbine & $140-150$ \\
\hline Pneumatic hammer & $120-130$ \\
\hline Industrial premises & 110 \\
\hline Stereo music & 100 \\
\hline Vehicle interior & $80-90$ \\
\hline Office premises & 70 \\
\hline Living area (refrigerator) & 60 \\
\hline Wind turbine at a distance of 200-250 m from the tower & 50 \\
\hline Urban noise in the bedroom & 40 \\
\hline Whisper & 30 \\
\hline Rustle of falling leaves & $10-20$ \\
\hline
\end{tabular}


A wind power station is an energy facility, which by itself implies its location on industrial lands, in particular energy. In the area where we plan to locate the object, such a territorial zone is not provided for in the Rules for Land Use and Development (RLUD) and the general plan of the municipality. In place of the selected investment sites, there is a functional zone of natural areas, according to the general plan of the municipality.

The region for the construction of the wind power station is chosen according to the principle of a relatively stable wind rose of the region. The Tyumen region, including the autonomous districts, is part of the 1st price zone and is an attractive region for the construction of a wind farm. In particular, it makes sense to consider such cities as Surgut, Nizhnevartovsk, Novy Urengoy, Salekhard, Tyumen. The figures show a wind rose with an average of five years.

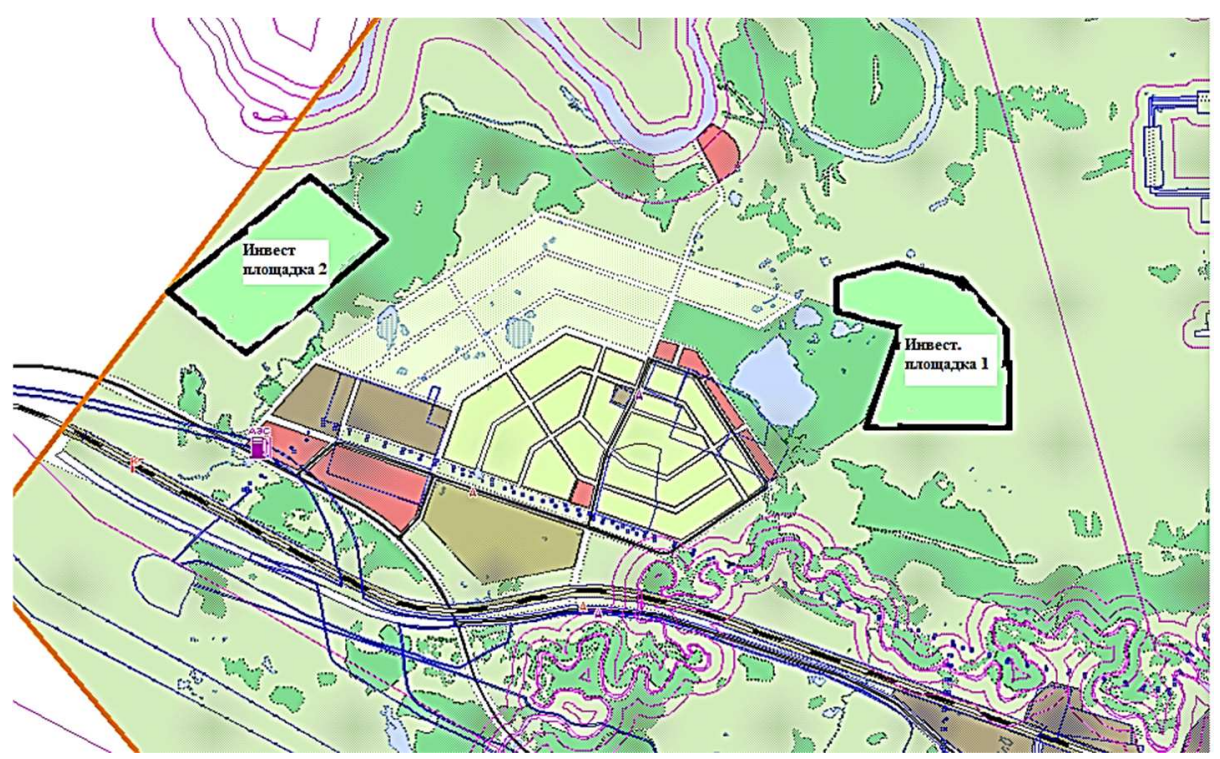

Functional areas:

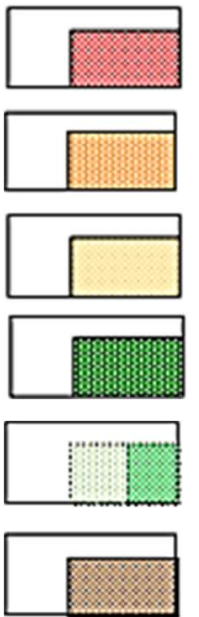

Public and business zone

Multi-storey residential area

Low-rise residential area

Recreational area

Natural areas zone

Industrial and communal storage area
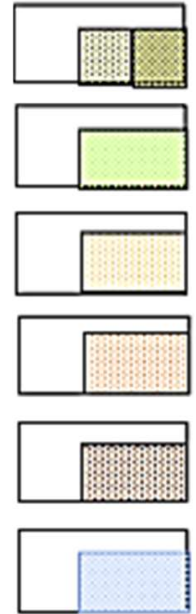

Transport area

Seasonal living area

Zone of promising low-rise residential development

Zone of promising mid-rise residential development

Zone of promising territories for industrial and communal storage purposes

Water objects

Fig. 1. The preliminary zone of the wind farm facility on the territory of the urban district of the city of Novy Urengoy according to the master plan. 
So, among several territories of the Tyumen region, according to the wind rose, it was the city of Novy Urengoy that was chosen. The planned capacity is approximately $38.5 \mathrm{MW}$, the station includes 14 wind power plants (hereinafter - WPP). On the public cadastral map of the urban district of Novy Urengoy, there are no suitable formed land plots for the implementation of the project. The authors of the article have formed two potential sites for the possible location of the wind farm.

The primary formation of a land plot takes place by the decision of the relevant authorities, local level, in this case, the administration of the municipal formation (AMF) of the urban district of Novy Urengoy. The basis for this will be the following documents:

Land surveying project that does not contradict the Urban Plan.

Project documents, which contain information about the sites.

If there is no project, then an approved scheme for the location of the land plot is required.

Table 3. Characteristics of the investment site.

\begin{tabular}{|l|l|l|}
\hline Investment site number & \multicolumn{1}{|c|}{ Plot № 1 } & \multicolumn{1}{|c|}{ Plot № 2 } \\
\hline Location & $\begin{array}{l}\text { Yamalo-Nenets Autonomous } \\
\text { Okrug, Novy Urengoy, to the } \\
\text { right of the Uralets microdistrict }\end{array}$ & $\begin{array}{l}\text { Yamalo-Nenets Autonomous } \\
\text { Okrug, Novy Urengoy, north } \\
\text { of the Uralets microdistrict }\end{array}$ \\
\hline Area, $\mathrm{m}^{2}$ & 75500 (approximate area) & 73 000 (approximate area) \\
\hline Permitted use & $\begin{array}{l}\text { Site for the construction of an } \\
\text { energy }\end{array}$ & $\begin{array}{l}\text { Site for the construction of an } \\
\text { energy }\end{array}$ \\
\hline Land category & $\begin{array}{l}\text { Before transfer: land of } \\
\text { settlements }\end{array}$ & $\begin{array}{l}\text { Before transfer: land of } \\
\text { settlements }\end{array}$ \\
\hline Transport infrastructure & $\begin{array}{l}\text { developed, the south-western } \\
\text { border of the site is adjacent to } \\
\text { the asphalt road }\end{array}$ & $\begin{array}{l}\text { developed, the south-eastern } \\
\text { border of the site is adjacent to } \\
\text { the asphalt road }\end{array}$ \\
\hline Power supply & $\begin{array}{l}\text { the source of power supply is } \\
\text { the substation «Airport» }\end{array}$ & $\begin{array}{l}\text { the source of power supply is } \\
\text { the substation «Airport» }\end{array}$ \\
\hline Water supply & $\begin{array}{l}\text { The laying of a water supply } \\
\text { system is available within the } \\
\text { boundaries of the nearby } \\
\text { Uralets microdistrict }\end{array}$ & $\begin{array}{l}\text { The laying of a water supply } \\
\text { system is available within the } \\
\text { boundaries of the nearby } \\
\text { Uralets microdistrict }\end{array}$ \\
\hline Gas supply & is absent & is absent \\
\hline
\end{tabular}

The package of documents for processing an application for the formation of a land plot includes:

- Boundary case, which will include the act of establishing boundaries.

- Map data. This means a drawing of a new site on the ground.

- The act of establishing boundary marks. In this case, the establishment must necessarily take place in the presence of persons authorized to carry out land surveying.

It is recommended to choose construction sites taking into account the following conditions:

- the soils that make up the site must allow the construction of buildings and structures, as well as the installation of appropriate equipment;

- the groundwater level should be below the depth of the basements of buildings and underground utilities;

- the surface of the site should be relatively flat with a slope providing surface drainage;

- the site should not be located in places of occurrence of minerals or in the zone of collapse of workings, in karst or landslide areas and areas contaminated with radioactive emissions, as well as in protective zones.

We take all these points into account for the selection of construction sites, with the aim of the subsequent formation of the land plot, we select the territory next to the Uralets microdistrict.

Below is a comparative table for the characteristics of the plots.

Site number 1 was chosen for the location of the wind farm. The main reason for choosing site number 1 is its remoteness from linear objects such as roads and waterworks. To make 
the placement of WPPs possible, it is necessary to transfer the existing functional zone «zone of natural areas» to «production zone». To do this, amendments are made to the general plan of the municipality and to the rules of land use and development.

In order to amend the general plan of the Ministry of Defense, the administration of the Ministry of Defense must initiate public hearings. The decision to prepare proposals for introducing amendments to the general plan is made, respectively, by the head of the local administration of the urban district of the city of Novy Urengoy.

\section{Discussion}

The main reasons for such a serious lag of Russia from the world trend are not the desire to shift the benchmark of the Russian economy from the enterprises of the oil and gas sector of the economy and the unwillingness to give up the low cost of nuclear energy production, thereby losing its leadership in the market of nuclear powers.

From the list of objective reasons preventing the launch of wind farms, one should include the traditional sources of energy production - water. Hydropower plants launched during the period of industrialization in the USSR have not exhausted their potential and resources.

The authors of the article highlight the key aspects of refusing to switch to non-traditional energy sources in relation to the domestic resource market:

1. Energy redundancy of sources and monopoly of wholesale suppliers, which is present in the country as a whole.

2. The inability of the consumer to independently resolve the issue of choosing an energy supplier, especially during the Soviet era.

3. Lack of initiatives, specialized knowledge and technologies, obstacles to the development of alternative energy methods.

For a comprehensive solution to the problem raised, it is necessary to consolidate decisions and actions at the state and business level with the involvement of foreign partner companies, which will allow to combine efforts and accelerate the development of the wind energy market in Russia in general, in the Tyumen region with the districts in particular. It is necessary to update the positions of the Roadmap for energy cooperation between Russia and the EU, with a change in the guidelines for renewable energy sources and the Roadmap for the development of the wind energy industry in Russia.

This actualization is extremely necessary, since in the medium term, according to the Remap-21 project, the total capacity of wind power plants on the wholesale electricity market in Russia can reach $23.3 \mathrm{GW}$ only by 2030 [5]. This would be enough to cover about $10 \%$ of Russia's energy supply. However, China annually installs more than $20 \mathrm{GW}$ of new wind energy capacity (in 2015, $33 \mathrm{GW}$ were installed [6]). At the same time, in other large wind markets such as Germany, India or the USA, the annual capacity increase is from 2 to $6 \mathrm{GW}[15,16]$.

\section{Conclusion}

The market potential in Russia for launching wind energy complex projects is great, as «the country has the world's largest technical and economic potential for wind energy, 16500 $\mathrm{TWh} /$ year. At the same time, the last competitive selection will lead to the construction in the near future on the territory of Russia of large wind farms with a total capacity of 700 $M W »[15]$. However, in order to bring Russian wind energy to a competitive global level, the Russian market will need to introduce a much larger volume of capacity, following the example of the intensity of the development of wind energy in China. 
Nevertheless, there is an interest in the construction of facilities based on wind and other renewable energy sources in Russia both from the state and from the business side. At the same time, serious infrastructural, financial and regulatory barriers have not been removed.

Summing up [15-19], we systematize the ways out of this situation.

The fastest way to restore the imbalance in the structure of energy production sources, following the example of industrialized countries, is to invite foreign investors to import technologies and build their own compact wind turbines in Russia. This way will reduce social risks associated with a drop in incomes of both legal entities and households due to stabilization, and further decrease in the cost of electricity.

The second way is through the acquisition of licenses and/or through partnerships with foreign companies, the creation of joint ventures. This path allows us to preserve national identity in the fuel and energy complex and a place for the development of our own technologies in energy production. For the end consumer, this path will entail a medium-term increase in the cost of electricity.

Both options have serious regulatory obstacles today due to the escalation of tensions in Russia's relations with industrialized countries.

The third way is an independent solution of technological issues in the creation of a national wind energy market through the consolidation of efforts of the educational, scientific and industrial environment of the Russian community.

The authors of the article emphasize the predominant features of the Tyumen region with the districts for launching compact wind turbines under a public-private partnership program through the implementation of the second path. The Tyumen Region is a strategically important and investment-attractive region of Russia, characterized by social stability, high rates of economic development and a high level of investment in fixed assets, in connection with which financial problems can be eliminated thanks to the support of regional investment development institutions.

One of the main conditions for the functioning of a wind farm are the following factors: the availability of a suitable location for the building and structure, the availability of a material and technical base, the ability to create a stream of regular customers. Due to the high quality of wind equipment, the possibility of interruptions in the supply of energy to the consumer is minimized, and therefore, for the time being, there is an orientation towards a foreign supplier by water transport in the North Sea.

Also, a foreign supplier guarantees a longer service life of the installation, which in turn reduces the cost of purchasing new equipment. For the implementation of the investment project of the wind power station, an investment site was selected in the city of Novy Urengoy, in the area of microdistrict Uralets. This site meets all the conditions for the placement of wind farm, its location does not intersect linear facilities (heating mains, water and gas supply facilities, transport infrastructure facilities, wildlife sanctuaries and reserves, cultural heritage sites, etc.).

The main object of energy consumption produced by the wind farm is planned to be located nearby. Thus, when a wind farm is connected to a power line, for a period when the operation of horticultural associations is not carried out, the station can become a spare branch, providing energy to areas of the city close to it. This will reduce the number of accidents on power grids.

The launch of such projects and the development of the Russian energy sector according to the «green» scenario will lead to a number of positive effects.

Firstly, it will allow revising the existing norms in the field of energy and significantly transforming them for further expansion in the field of using alternative energy sources.

Secondly, «green» energy will become widespread in the region, which will provide the isolated areas of the region with an uninterrupted supply of energy due to renewable energy sources. 
Thirdly, the wind farm can be used as a backup line to provide energy to certain parts of the city in the event of an accident at the existing thermal power plants.

Fourth, wind farms will save hydrocarbon fuel.

Fifth, it will help ensure the fulfillment of Russia's international obligations, such as the main provisions of the Kyoto Protocol and the UN convention on the preservation of the environment and climate, as well as environmental and ecological standards of the Russian Federation.

\section{References}

1. Developed countries-leaders in installed capacity of wind power plants. A source: https://energo.house/veter/strana-lider-ves.html.

2. PJSC «Fortum», projects under implementation. A source: https://www.fortum.ru/ razvitie-vetroenergetiki-v-rossii.

3. Wind energy in Russia: application of the largest wind farms: their efficiency and development prospects. A source: https://energo.house/veter/vetroenergetika-vrossii.html\#i.

4. Energy market in Russia. A source: https://www.fortum.ru/o-nas/elektrichestvo-iteplo/energorynok.

5. WWEA publishes «World wind resource assessment Report». A source: http://www.wwindea.org/wwea-publishes-worldwind-resource-assessment-report.

6. Energy and industry in Russia. Electric power and heat power, generation and power grids, enterprises and energy specialists. A source: https://www.eprussia.ru/epr/379380/6480891.htm.

7. On approval of the scheme and program for the development of the electric power industry of the Tyumen region for 2020-2025: order of the Governor of the Tyumen region of April 30 37-R, (2020).

8. UNFCCC, 2015. Russian Submission INDC. United Nations Framework Convention on Climate Change, Bonn. A source: https://unfccc.int/sites/default/files/conveng.pdf.

9. V.V. Elistratov. Renewable energy. 3rd ed., add. St. Petersburg: Publishing House of the Polytechnic University. un-t, 424 (2016).

10. Renewable energy sources in Russia: how wind-power engineering developing. A source: https://recyclemag.ru/article/rossii-razvitie-skorostyu-vetra.

11. Four scenarios for the development of renewable energy sources for Russia. A source: $\mathrm{http}: / /$ tass.ru/pmef-2016/article/3348989.

12. Electric power industry for the country or the country for the electric power industry?. Energy and Industry of Russia 7 (411), (2021).

13. Variable speed wind generator $S G$ 3.4-132 A source: https:// www.siemensgamesa.com/ en-int/products-and-services/onshore/wind-turbine-sg-3-4-132.

14. SE14630 WTG Planetary Gear Wind Generator. A source: https://www.directindustry. com.ru/prod/sany/product-52887-2293376.html.

15. Prospects of wind energy in Russia. A source: https://renen.ru/prospects-of-wind-powerin-russia.

16. Prospects of energy market in Russia. A source: http://wwindea.org/perspectives-of-thewind-energy-market-in-russia-launched.

17. Features of investments in the Russian electric power industry on market conditions. Energy and Industry of Russia 7 (411), (2021).

18. China sets record for wind farm commissioning. A source: https://www.vedomosti.ru/ opinion/articles/2021/01/21/855023-kitai-rekord.

19. Paris Agreement-agreement under the United Nations Framework Convention on Climate Change. A source: http://docs.cntd.ru/document/542655698. 